\title{
IJBF ESTIMATING THE EARLY EXERCISE PREMIUM OF AMERICAN PUT INDEX OPTIONS
}

\author{
Ako Doffou
}

Sacred Heart University, United States of America

\begin{abstract}
This paper examines empirically the value of early exercise by testing the ability of two American put valuation models to predict the early exercise premium for the S\&P 100 American put options. An accuracy test and a quality test are performed on (1) the MacMillan and Barone-Adesi and Whaley model, and (2) the Carr, Jarrow and Myneni model. The test results show that early exercise premium is significant regardless of moneyness. Moreover, consistent with the theory, the value of early exercise is significantly negatively related to moneyness and interest rates and significantly positively related to time to maturity and to the volatility of the underlying index. Both American put valuation models examined do not fully capture the value of early exercise embedded in American put prices.
\end{abstract}

JEL Classification: G13

Key words: Option prices, Early exercise, Moneyness, S\&P American put option

\section{Introduction}

The value of early exercise or early exercise premium is the difference in price between an American option and an otherwise identical European option. It is difficult to estimate the early exercise premium because American and European options rarely have the same state variable or underlying asset. Using transaction data on both American and European foreign currency options traded at the Philadelphia Stock Exchange, Jorion and Stoughton (1989) directly computed the actual value of early exercise for foreign currency options. The average value of the premium found was about two percent of the option price. They also tested the Geske and Johnson (1984) American option pricing model by regressing observed early exercise premium over model predicted early exercise premium. They concluded that the Geske-Johnson model tracks well the variation in 
the true early exercise premium. With the exception of foreign currencies, other state variables driving both the American option and otherwise identical European option do not exist. Hence, estimation of early exercise premium from direct comparison is not possible for options whose underlying assets are not currencies.

Shastri and Tandon (1986) and Whaley (1986) propose an alternative approach to estimate the value of early exercise for futures options by computing the difference between the price given by an American option pricing model and that given by the Black-Scholes model. Using the Geske-Johnson futures options valuation model, Shastri and Tandon (1986) showed that the value of early exercise is significant only for in-the-money options with a fairly long time-tomaturity. Whaley (1986) found identical result that early exercise premium for out-of-the -money futures options is negligible.

Because of the significant and systematic pricing biases inherent in most American put option valuation models, using any model dependent technique to estimate the early exercise premium is problematic. Brenner and Galai (1986) proposed the use of the put-call parity relationship to estimate the value of early exercise for American options. Given the observable prices for put options, call options and the underlying stock, they derive the implied risk free interest rate from the put-call parity arbitrage condition and use this risk-free rate to estimate the value of early exercise. Using IBM option data from the Chicago Board Options Exchange (CBOE) from June 1977 to August 1978, Brenner and Galai found an average early exercise premium of 0.9 per cent for at-the-money put options and 3.5 per cent for in-the-money put option.

Zivney (1991) takes a similar but modified approach to estimate early exercise premium as the difference between the American option price and the European option price derived from put-call parity. The data used consist of the S\&P 100 index options for which Harvey and Whaley (1992) found the dividend stream to be distinctly discrete and early exercise for both calls and puts to occur frequently. Estimates of early exercise premium are analyzed separately for cases where calls are in-the-money and for cases where puts are in-the-money. Zivney found an average value of early exercise of 10 percent for put options and 3.5 per cent for call options on the S\&P 100 index. This approach does not pick up the misspecification of the stochastic process for stock prices inherent in option pricing models and suffers from inherent biases induced when estimating a put-call parity implied riskless rate. Moreover, the estimated values for early exercise for put options were contaminated by those for call options, making it impossible to separate the two.

Loudon (1990) compares the predictive ability of the put-pricing model developed by MacMillan (1986) and Barone-Adesi and Whaley (1987) to that of the Black-Scholes European model. He finds systematic pricing errors in the American put option pricing model with the American model put prices being significantly closer to market prices than are the Black-Scholes European model prices. 
Mispricing by American put valuation models may arise when these models misspecify the dynamics of stock prices and the behavior of other option parameters, and when the early exercise feature is not properly accounted for. Dueker and Miller (2003) measure directly the early exercise premium using American and European S\&P 500 index options. Using mid-points from bid-ask quotes, Dueker and Miller find that the early exercise premium for the American S\&P 500 index put options is between $7.97 \%$ and $10.86 \%$ of the option price and the estimated premium is most likely biased. This result is consistent with Dueker and Miller (1996) in which an adjustment to liquidity biases reduces the value of early exercise premium for the S\&P 500 index options from $\$ 0.22$ to $\$ 0.19$.

Carr, Jarrow, and Myneni (1992), herein refereed to as CJM model, show that the early exercise premium is an exact solution to the Black-Scholes or (BS) American put option price with moving boundary conditions in contrast to the approximations by MacMillan (1986) and Barone-Adesi and Whaley (1987) or MBAW model. Hence, the CJM model gives theoretically better results than the MBAW model which is a quadratic approximation of the Black-Schole's partial differential equation.

The results from previous studies seem to indicate that existing American put option pricing models do not fully capture the market value of early exercise. This paper examines empirically the value of early exercise and tests the ability of the CJM and MBAW American put valuation models to predict the value of early exercise for American put options. The market values of early exercise are derived using Rhim and Kim (2000) methodology which does not rely on any particular option pricing model. Assuming that the European put-call parity holds and that investors are rational, the European put value embedded in an American put price can be derive from the put-call parity relationship. The market values of early exercise are then easily obtained as the difference between the observed market prices of American put options and the derived European put option values. Using the S\&P 100 index options transaction prices, this study finds that the values of early exercise are statistically significant for in-the-money and at-the-money put options.

To get reliable estimates of the values of early exercise, the accuracy and quality of the MBAW and CJM American put valuation models are tested. The accuracy of each model is tested by comparing model-predicted values to observed market values. Pricing biases are measured as absolute differences between market prices and theoretical prices predicted by the MBAW and the CJM models. To further investigate the pricing biases, they are decomposed into two components: mispricing of the early exercise premium and mispricing of the European option price component caused by the misspecification of the BlackScholes formula.

The quality of an American put valuation model is tested by examining how well the model captures the true value of early exercise premium. The results are consistent with previous work and confirm that American put option valuation models do not fully capture the value of early exercise. 
The rest of the paper is organized as follows. Section 2 introduces the model. The test methodologies are explained in section 3. Section 4 describes the data set used. The empirical results are analyzed in section 5. Finally, section 6 concludes the paper.

\section{The Model}

The theoretical value of early exercise can be estimated as the difference between the option price generated by an American option pricing model and the price of a corresponding European option obtained from the Black-Scholes model. This approach implicitly assumes that both American and European option pricing models generate correct prices. Prior empirical studies show that both American and European option pricing models misprice actual market prices. The mispricing by theoretical models may arise from a misspecification of the stock price dynamics.

To avoid problems caused by model misspecification, an estimation method that does not rely on any particular option pricing model is used. It is assumed that option markets are efficient and therefore that the European putcall parity holds. It is assumed further that investors are rational in that holders of American call options do not prematurely exercise their call options when no dividends are to be paid on the underlying stock until option maturity. Based on these assumptions, the European put-call parity relationship is reconstructed by replacing a European call with an American call as follows:

$$
P_{E}+S=C_{A}+K e^{-r T}
$$

where $C_{A}$ and $P_{E}$ are respectively the value of an American call option and the value of a European put option with the same strike price $K$ and the same maturity $T$. From equation (1) above, we derive the market value of a European put option:

$$
P_{E}=C_{A}-S+K e^{-r T}
$$

The early exercise premium embedded in the American put option, $E E P_{m k t}$, can be obtained by subtracting the European put value imputable to put-call parity from the observed market price $P_{A}$ of the American put option:

$$
E E P_{m k t}=P_{A}-\left(C_{A}-S+K e^{-r T}\right)
$$

The four parameters that affect the option price also affect the option early exercise premium. These parameters are the option moneyness $S / K$, the volatility of the underlying stock/index price $\sigma$, the time to maturity of the option $T$, and the risk-free interest rate $r$. These parameters are picked up by two major factors that directly affect the value of early exercise. The first factor is the critical stock price which triggers immediate exercise of the put option. The other factor is 
the time value of money. The critical stock price, $S_{C}$, is the maximum stock price at which it is optimal to exercise the put option immediately. This critical stock price is reached when the time value is zero or close to zero so that the put price is equal to its intrinsic value. Hence, the critical stock price is obtained by solving the following equation

$$
K-S_{C}=P\left(S_{C}, K, t, r, \sigma\right)
$$

The critical stock price depends on all the option pricing parameters except the current stock price. A rise in the critical stock price leads to a greater value for the early exercise premium because it makes a put option more likely to be in the money and therefore more likely to be exercised early.

The value of early exercise is also affected by the interest to be earned on the strike price that would be received in the event the put option is exercised early. The interest earned on the strike price is the difference between the strike price and the present value of the strike price or $K\left(1-e^{-r T}\right)$. Because the time value of money on interest income is a function of the strike price, interest rate, and the time to maturity, a greater time value of money creates a greater value of early exercise.

A decrease in moneyness due to a stock price increase will decrease the value of early exercise. Using the Black-Scholes formula, It can be shown that the partial derivative of the critical stock price with respect to the strike price in

equation (4) is exactly equal to $\frac{N\left(d_{2}\right)}{N\left(d_{1}\right)}$ which is strictly positive. Hence, a higher strike price increases the critical stock price and therefore increases the value of early exercise. Moreover, an increase in the strike price increases the interest income that can be earned on the strike price when the put option is exercised.

An increase in the volatility of the underlying stock price makes the put option more likely to be in the money and therefore increases the value of early exercise. An increase in the time-to-maturity increases the value of the put option as well as the time value of money and therefore increases the value of early exercise. When interest rates increase, the present value of the strike price decreases, making put options less valuable. Hence, as interest rates increase, it is more likely for put options to be out of the money, and therefore less likely for put options to be exercised early. Moreover, as interest rates increase, the time value of money increases. Therefore, the early exercise premium for a put option may increase, decrease, or remain constant when interest rates increase.

In the paragraph that follows, the test methodologies for both the MBAW and CJM models are discussed.

\section{Test Methodologies}

\subsection{MacMillan, Barone-Adesi and Whaley Model and Tests}

Both American and European option prices satisfy the Black-Scholes partial differential equation. It follows that the early exercise premium which is the difference in prices between an American option and an otherwise identical 
European option must also satisfy the same partial differential equation. Using a quadratic approximation technique, a solution for an American put valuation formula $P_{A}$ is

$$
P_{A}=P_{E}+\delta\left(\frac{S}{S_{C}}\right)^{y} \text { for } S>S_{C} \text {, and } P_{A}=K-S \text { for } S<S_{C}
$$

where $P_{E}$ is the Black-Scholes European put price, $\delta=-\left(\frac{S_{C}}{y}\right)\left[1-N\left(-d_{1}\left(S_{C}\right)\right)\right]$, and $y=\left(\frac{1}{2}\right)\left[-\left(\frac{2 r}{\sigma}-1\right)-\left(\left(\frac{2 r}{\sigma}-1\right)^{2}+\frac{8 r}{\sigma\left(1-e^{-r(T-t)}\right)}\right)^{\frac{1}{2}}\right] . \quad$ The put option strike price is $K$. The critical stock price below which it is optimal to exercise the put option immediately is $S_{C}$ which is obtained by solving the following equation

$$
K-S_{C}=P_{E}\left(S_{C}\right)+\delta
$$

Assuming that the prices generated by both the MBAW and the BlackScholes models are correct, the theoretical value of early exercise, $E E P_{m d l}$, for an American put option can be estimated as follows

$$
E E P_{m d l}=P_{A_{m d l}}-P_{E_{m d l}}
$$

where $P_{A_{m d l}}$ is the MBAW model American put option price and $P_{E_{m d l}}$ the Black-Scholes European put option price.

The theoretical value of early exercise given in equation (7) above is compared to the actual value of early exercise estimated directly from observed market put prices. The difference between model-predicted values of early exercise and actual observed market values of early exercise reveals the extent to which the American put option pricing models considered do not capture the early exercise premium embedded in American put option prices.

There are two critical problems in testing any option pricing model. The first problem is that a test of any option pricing model is a joint test of market efficiency and model validity. The second problem is that stock price volatility is not directly observable. To solve the first problem, a filtered sample is used which excludes all observations that violate the no-arbitrage boundary conditions for American put-call parity. To get a proper estimate of the stock price volatility, the MBAW model is assumed to generate a correct price for a put option when the put option is at-the-money. The implied volatility is derived from the MBAW model by fitting the model to the at-the-money put option prices. The resulting implied volatility is then used to predict remaining put prices. It follows that the validity of the tests conducted here lies on the accuracy of the volatility estimation.

The MBAW model is tested in two ways. First, the accuracy of the model is tested by comparing the model predicted prices to the observed market prices. 
Second, the quality of the MBAW model is tested by investigating how well this American put valuation model captures the actual value of early exercise. In measuring the accuracy of the MBAW model, its pricing biases $P B_{A M}$ are computed as follows

$$
P B_{A M}=P_{A_{m k t}}-P_{A_{m d l}}
$$

where $P_{A_{m k t}}$ is the observed market value of the American put option and $P_{A_{m d l}}$ the MBAW model price.

The MBAW model implicitly assumes that the Black-Scholes model correctly prices the European portion of an American put option. It follows that pricing biases from the MBAW model may arise from the misvaluation of early exercise premium and from the misspecification of the Black-Scholes formula. Hence, the MBAW pricing biases can be decomposed as follows

$$
P B_{A M}=P E_{B S}+P E_{E E X}
$$

where $P E_{B S}$ is the pricing error due to the Black-Scholes model misspecification and $P E_{E E X}$ the pricing error associated with the misvaluation of early exercise premium. The pricing error related to the Black-Scholes model misspecification is evaluated as the difference between the Black-Scholes European put price, $P_{A_{m k t}}$, and the market value of a European put option, $P_{A_{m d l}}$, derived from European put-call parity as follows

$$
P E_{B S}=P_{E_{m k t}}-P_{E_{m d l}}
$$

The pricing error caused by the misvaluation of early exercise premium is assessed as the difference between the actual market value of early exercise, $E E P_{m k t}$, and the model predicted value of early exercise, $E E P_{m d l}$,

$$
P E_{E E X}=E E P_{m k t}-E E P_{m d l}
$$

The quality or performance of the MBAW model is evaluated by examining how well this model captures the actual market value of early exercise. The degree to which the MBAW model misprices the true market values of early exercise, $D M$, is given by

$$
D M=\left(1-E E P_{m d l} / E E P_{m k t}\right)(100)
$$

To further evaluate the quality of the MBAW model, market values of early exercise premium are regressed over model-predicted values of early exercise premium. The regression equation is

$$
E E P_{m k t}=\lambda_{1}+\lambda_{2}\left(E E P_{m d l}\right)+\omega
$$


Under the null hypothesis that the model-predicted early exercise premium perfectly forecasts the true market value of early exercise premium, the intercept coefficient, $\lambda_{1}$, should equal zero and the slope coefficient, $\lambda_{2}$, should equal one.

\subsection{Carr, Jarrow and Myneni Model and Tests}

The Carr, Jarrow, and Myneni (1992) model or CJM model shows the early exercise premium as an exact solution to the Black-Scholes or BS model American put option price with moving boundary conditions as opposed to the approximation approach of the MBAW model. Consequently, the CJM model gives theoretically better results than the MBAW model which is a quadratic approximation of the Black-Scholes partial differential equation. However, the CJM model has a singularity problem at time zero (i.e., option at maturity) and therefore has no known analytic solution. If an option is at expiration, the numerical approximation is the only alternative to the CJM exact solution.

In this paper, the performance of the MBAW model and the CJM model are compared. The tests undertaken for the CJM model are exactly the same as those described above for the MBAW model. The MBAW model provides computing efficiency even though the CJM model is theoretically superior. Whether or not the CJM model performs significantly better than the MBAW model to offset its relative computing time inefficiency is an empirical question not yet answered

\section{The Data}

Daily transaction data for put and call options on the S\&P100 index (OEX) traded on the Chicago Board of Options Exchange (CBOE) are used. The data set spans over a ten-year period from January 3, 1995 to January 3, 2005. The data consist of the time and price of every transaction in which the price changed from the previous transaction for the ten-year period considered. The initial data set contains 362,847 OEX index options. All OEX put-call pairs that meet the requirements that follow are selected and are used to compute early exercise premium. Both put and call options in a put-call pair are options on the same underlying stock index, with the same strike price and the same maturity. Bidand-ask data were discarded since no transactions were conducted at those prices. Only contracts with maturities between one and four months are retained. Longer maturities were too thinly traded, and shorter maturities were too close to the maturity date to contain useful information about early exercise premium. To avoid days with thin trading, at least 20 call and 20 put transactions are required for any given day's data to be retained. Transactions in at least four strike classes for calls and four for puts are required to ensure a range of "moneyness" sufficient to provide a good picture of the distribution of early exercise premium. Deep-out-of-the-money call and put options defined as those with prices less than 5 cents, are deleted from the sample. For these options, the bid-ask spread is a big proportion of their time value. Therefore, their implied volatilities would be highly sensitive to the bid-ask bounce. Put and call option prices in a retained 
put-call pair must satisfy the no-arbitrage boundary conditions for American put-call parity. Finally, the early exercise premium of a put option cannot be greater than the put option price.

All of the above criteria eliminate 243,906 put and call options from the sample, leaving only a total of 118,941 put-call pairs for the estimation of early exercise premium. The daily risk-free interest rate is computed from the prices of Treasury bills maturing close to the maturity of the option. The tests conducted use two volatility measures. The historical volatility (HV) is obtained with daily index returns for the previous 180 trading days. The implied volatility (IV) is derived using the methodology proposed in Whaley (1982).

\section{Empirical Results}

The actual market value of early exercise for American put options is given by equation (3). While previous empirical studies estimate the value of early exercise based on model-predicted prices, this study estimates early exercise premium from actual market prices. Table 1 shows the mean market values of early exercise for American put options on OEX Index for the period 01/03/1995 $-01 / 03 / 2005$, for all options and for all degrees of moneyness as percentage of the put option market prices. For all options, the average value of early exercise is $\$ 7.436$ or 9.55 percent of the put option market price. The mean market value of early exercise for in-the-money put options $(\$ 11.013)$ is greater than that for at-the-money put options (\$5.237) which in turn is greater than that for out-ofthe money put options $(\$ 4.411)$. The average value of early exercise is 3.427 percent for all out-of-the-money put options compared to 14.622 percent for all in-the-money options. This finding is consistent with the fact that out-of-themoney options contain a negligible value of early exercise.

Numbers in parentheses are mean market values of early exercise expressed as a

Table 2 displays the model predicted mean values of early exercise for American put options on OEX Index for the period 01/03/1995 - 01/03/2005. Model predicted values of early exercise are estimated as the difference between (1) the theoretical American put option price given by the MacMillan, BaroneAdesi and Whaley (MBAW) model or the Carr, Jarrow and Myneni (CJM) model, and (2) the Black Scholes European put option price. The values in parentheses are the mean values of model-predicted early exercise expressed as a percent of the put price given by the model. The computations based on implied volatility show that the MBAW model predicts a mean early exercise premium of $\$ 4.42$ for in-the-money put options and $\$ 0.33$ for out-of-the-money put options, while the CJM model predicts a mean exercise premium of $\$ 4.62$ for in-the-money put options and $\$ 0.29$ for out-of-the-money put options. These models predicted mean values of early exercise are substantially lower than the mean market values of early exercise computed in Table 1, an indication that the MBAW and the CJM American valuation models undervalue the early exercise premium. 
This result is sustained when the model predicted mean values of early exercise are computed based on historical volatility. Table 2 also shows that computations based on historical volatility lead to a wider gap for the mean value of early exercise between the in-the-money options and out-of-the-money options.

TABLE 1: Mean market values of early exercise for American put options on OEX Index: 01/03/1995 - 01/03/2005.

\begin{tabular}{lcc}
\hline & Number of Observations & $\begin{array}{c}\text { Mean Market Value of Early } \\
\text { Exercise }\end{array}$ \\
& 52,025 & 11.013 \\
In-the-money & & $(14.622)$ \\
\multirow{2}{*}{ At-the-money } & 19,699 & 5.237 \\
Out-of-the-money & 47,217 & $(10.829)$ \\
\multirow{2}{*}{ All } & \multirow{2}{*}{111,941} & $(3.411$ \\
& & 7.436 \\
\end{tabular}

Consistent with equation (3), market values of early exercise premium are defined as observed market price of American put option minus the European put value of the option derived from put/call parity. The average bid and ask yield quotations on Treasury bills that expire closest to the option's expiration date are used as estimates for the risk-free rate of interest. The values in parentheses are mean market values of early exercise expressed as a percentage of the put option market price.

TABLE 2: Model Predicted Mean Values of Early Exercise for American Put Options on OEX Index: 01/03/1995 - 01/03/2005.

\begin{tabular}{lccccc}
\hline & $\begin{array}{c}\text { Number of } \\
\text { Observations }\end{array}$ & $\begin{array}{c}\text { MBAW } \\
\text { H.V }\end{array}$ & $\begin{array}{c}\text { CJM } \\
\text { H.V }\end{array}$ & $\begin{array}{c}\text { MBAV } \\
\text { I.V }\end{array}$ & $\begin{array}{c}\text { CJM } \\
\text { I.V }\end{array}$ \\
\hline In-the-money & \multirow{2}{*}{52,025} & 5.78129 & 5.93864 & 4.42129 & 4.61518 \\
& & $(7.12458)$ & $(7.41797)$ & $(5.23872)$ & $(5.53892$ \\
At-the- & \multirow{2}{*}{19,699} & 0.69173 & 0.72479 & 0.71026 & 0.73148 \\
money & $(3.61192)$ & $(3.76726)$ & $(2.59809)$ & $(2.73949)$ \\
Out-of-the- & \multirow{2}{*}{47,217} & 0.25164 & 0.22471 & 0.32812 & 0.29036 \\
money & & $(3.20478)$ & $(2.19897)$ & $(1.69968)$ & $(1.44648)$ \\
All & \multirow{2}{*}{118,941} & 2.74320 & 2.80680 & 2.18177 & 2.25510 \\
& & $(4.98674)$ & $(4.74151)$ & $(3.39646)$ & $(3.45067)$ \\
\hline
\end{tabular}

MBAW stands for the MacMillan, Barone-Adesi and Whaley model values, while CJM stands for the Carr, Jarrow and Myneni model values. Model predicted values of early exercise are estimated as the difference between (1) the theoretical American put option price given by the MBAW model or the CJM model, and (2) the Black Scholes European put option price. H.V. and I.V. are historical volatility and implied volatility respectively. The values in parentheses are mean values of model-predicted early exercise expressed as a percent of model put price. 
To test the relationship between early exercise premium and option parameters, market values of early exercise are regressed on four option parameters: option moneyness measured by the stock price over the strike price, time to maturity, volatility of the underlying stock/index price, and interest rates. The results of these regressions are displayed in Table 3.

TABLE 3: Market Values of Early Exercise, $\mathrm{EEP}_{\mathrm{mkt}}$, are Regressed on Put Option Moneyness, Time to Maturity, Volatility of the Stock Price and Interest Rate:

$$
E E P_{m k t}=\alpha+\beta_{1}\left(\frac{S}{K}\right)+\beta_{2}(\text { time to maturity })+\beta_{3}(\text { volatility })+\beta_{4}(\text { interest rate })+\varepsilon
$$

\begin{tabular}{cllllll}
\hline $\begin{array}{l}\text { Number of } \\
\text { Observations }\end{array}$ & $\alpha$ & $\beta_{1}$ & $\beta_{2}$ & $\beta_{3}$ & $\beta_{4}$ & Adj $-R^{2}$ \\
\hline 118,941 & -0.03865 & -0.00239 & 0.34862 & 0.00186 & -0.05271 & 0.3685 \\
& $(-10.2735)$ & $(-21.3814)$ & $(87.5975)$ & $(17.9108)$ & $(-41.3829)$ & \\
\hline
\end{tabular}

The signs of the coefficient estimates are consistent with the theory. As the moneyness defined by $S / K$ increases, the put option is more likely to be out-of-the money and therefore less valuable. Hence, the early exercise premium decreases as the moneyness increases which is consistent with a negative sign for the $\beta_{1}$ coefficient. As the time to maturity increases, a put option value increases, making the early exercise premium more valuable. Hence, the sign of the $\beta_{2}$ coefficient is positive. As the volatility increases, a put option price increases, making the early exercise premium more valuable. Therefore, the sign of the $\beta_{3}$ coefficient is positive. As interest rates increase, the present value of the strike price decreases, making it more likely for the stock price to be above the strike price. Hence, as interest rates increase, the put option will more likely be out-of-themoney, making the early exercise premium less valuable. This corresponds to a negative sign for the $\beta_{4}$ coefficient.

The value of early exercise premium, $\mathrm{EEP}_{\mathrm{mkt}}$, is computed as the difference between (1) the price of the American put option observed in the market and (2) the price of the European put option derived from put/call parity. Implied volatility measures are used to estimate this regression model. The time-to-maturity is derived as the number of days to maturity divided by 365 days. The daily risk-free interest rate is computed from the prices of Treasury bills maturing close to the maturity of the options. The numbers in parentheses are t-statistics.

The signs of the coefficient estimates are consistent with the theory. As the moneyness defined by $S$ / $K$ increases, the put option is more likely to be outof-the-money and therefore less valuable. Hence, the early exercise premium decreases as the moneyness increases which is consistent with a negative sign for the $\beta_{1}$ coefficient. As the time to maturity increases, a put option value increases, making the early exercise premium more valuable, consistent with a positive sign for the $\beta_{2}$ coefficient. As the volatility increases, a put option price 
increases, making the early exercise premium more valuable, consistent with a positive sign for the $\beta_{3}$ coefficient. As interest rates increase the value of a put option decreases making the early exercise premium less valuable consistent with a negative sign for the $\beta_{4}$ coefficient. The value of early exercise premium, $E E P_{m k t}$, is computed as the difference between (i) the price of the American put option observed in the market and (ii) the price of the European put option derived from put/call parity as given in equation (3). Implied volatility measures are used to estimate this regression model. The time to maturity is measured as the number of days to maturity divided by 365 days. The daily risk-free interest rate is computed from the average bid and ask yield quotations on Treasury bills maturing closest to the maturity of the option. The numbers in parentheses are tstatistics. Overall, the regression results show that the early exercise premium is significantly positively related to time to maturity and volatility and significantly negatively related to meneyness and interest rates.

The empirical results of the accuracy test of the valuation models used are reported in Tables 4 . The accuracy of the model is tested by comparing modelpredicted values to observed market values. Table 4 shows the mean absolute percentage option pricing error by moneyness. This statistic is defined as the difference between the model price and the observed market price of the put option divided by the market price of the put option. The MBAW and CJM models perform more accurately under implied volatility (IV) than under historical volatility (HV), consistent with previous work in the finance literature. The Black-Scholes model (BS) performs better under historical volatility than under implied volatility. American put valuation models attempt to predict American put prices by approximating the value of early exercise. For in-the-money put options, market prices reflect mainly their intrinsic values. For out-of-the-money put options, market prices consist mainly of their time values. Hence, out-ofthe-money options are subject to more pricing errors than in-the-money options. This assertion is supported by the mean absolute percentage option pricing error by moneyness reported in Table 4. For the MBAW and CJM models with IV, the mean absolute percentage pricing error is 2.05 percent and 2.00 percent respectively, for all in-the-money options and 5.66 percent and 5.74 percent respectively, for all out-of-the-money put options. This result is consistent with Blomeyer and Johnson (1988). The models with IV price more accurately than the same models with HV.

Because both the MBAW and CJM models implicitly assume that the BlackScholes model correctly prices European values of American put options, pricing biases reported for these models inherently contain pricing errors resulting from the Black-Scholes model's misspecification of the stock price dynamics. For the Black-Scholes model, Table 4 reports a mean absolute percentage pricing error of 7.81 percent and 6.42 percent using implied volatility and historical volatility respectively for in-the-money put options. For out-the-money options, the numbers are 19.45 percent and 17.27 percent under IV and HV respectively. Hence, the Black-Scholes model's misspecification is more pronounced in pricing out-of-the-money put options than in pricing in-the-money put options. 
TABLE 4: Option Models Pricing Biases: Mean Absolute Percentage Option Pricing Error by Moneyness.

\begin{tabular}{|c|c|c|c|c|c|c|c|}
\hline & $\begin{array}{l}\text { Number of } \\
\text { Observations }\end{array}$ & $\begin{array}{c}\text { MBAW } \\
(\text { H.V })\end{array}$ & $\begin{array}{l}\text { CJM } \\
\text { (H.V) }\end{array}$ & $\begin{array}{c}\text { BS } \\
\text { (H.V) }\end{array}$ & $\begin{array}{c}\text { MBAW } \\
(\text { H.V })\end{array}$ & $\begin{array}{l}\text { CJM } \\
\text { (I.V) }\end{array}$ & $\begin{array}{l}\text { BS } \\
\text { (I.V) }\end{array}$ \\
\hline $\begin{array}{l}\text { In-the- } \\
\text { money }\end{array}$ & 52,025 & 4.2831 & 4.1937 & 6.4228 & 2.0543 & 2.0075 & 7.8109 \\
\hline $\begin{array}{l}\text { At-the- } \\
\text { money }\end{array}$ & 19,699 & 7.8694 & 7.8429 & 11.6481 & 4.5712 & 4.3918 & 15.1404 \\
\hline $\begin{array}{l}\text { Out- } \\
\text { of-the- } \\
\text { money }\end{array}$ & 47,217 & 12.2573 & 12.4521 & 17.2707 & 5.6628 & 5.7404 & 19.4461 \\
\hline All & 118,941 & 8.0426 & 8.0765 & 11.5946 & 3.9036 & 3.8843 & 13.6437 \\
\hline
\end{tabular}

The mean absolute percentage option pricing errors are computed for the MacMillan (1986) and Barone-Adesi \& Whaley (1987) model (MBAW), the Carr, Jarrow and Myneni (1992) model (CJM), and the Black-Scholes (1973) model (BS). These computations are done using both historical volatility (H.V) and implied volatility (I.V). The mean absolute percentage option pricing error is defined as the absolute value of the difference between the model price and the observed market price divided by the market price of the put option

TABLE 5: Mispricing of Early Exercise Premium for American Put Options on OEX Index: 01/03/1995 - 01/03/2005.

\begin{tabular}{lccccc}
\hline & $\begin{array}{c}\text { Number of } \\
\text { Observations }\end{array}$ & $\begin{array}{c}\text { MBAW } \\
(\mathrm{H} . \mathrm{V})\end{array}$ & $\begin{array}{c}\text { CJM } \\
(\mathrm{H} . \mathrm{V})\end{array}$ & $\begin{array}{c}\text { BS } \\
(\mathrm{H} . \mathrm{V})\end{array}$ & $\begin{array}{c}\text { MBAW } \\
(\mathrm{H} . \mathrm{V})\end{array}$ \\
\hline $\begin{array}{l}\text { In-the- } \\
\text { money }\end{array}$ & 52,025 & $\begin{array}{c}5.2317 \\
(48.3105)\end{array}$ & $\begin{array}{c}5.0744 \\
(43.9843)\end{array}$ & $\begin{array}{c}6.5917 \\
(52.7835)\end{array}$ & $\begin{array}{c}6.3978 \\
(47.2425)\end{array}$ \\
$\begin{array}{l}\text { At-the- } \\
\text { money }\end{array}$ & 19,699 & 4.5453 & 4.5122 & 4.5267 & 4.5055 \\
$\begin{array}{l}\text { Out- } \\
\text { of-the- } \\
\text { money }\end{array}$ & $(71.3251)$ & $(68.4893)$ & $(71.8931)$ & $(68.5547)$ \\
All & 47,217 & 4.1594 & 4.1863 & 4.0829 & 4.1206 \\
& $183.4691)$ & $(84.5722)$ & $(82.0743)$ & $(83.2172)$ \\
& 118,941 & 4.6923 & 4.6257 & 5.2538 & 5.1804 \\
& $(65.4271)$ & $(63.1082)$ & $(67.3314)$ & $(66.0452)$ \\
\hline
\end{tabular}

The mispricing of early exercise premium is computed for the MacMillan, BaroneAdesi and Whaley model (MBAW) and, the Carr, Jarrow and Myneni model (CJM). The mispricing is the difference between the market value of early exercise premium and the model predicted value of early exercise premium. The computations are performed using both historical volatility (H.V.) and implied volatility (I.V.). The values in parentheses are mean values of the mispricing expressed as a percent of the market value of early exercise premium. 
The quality of an American put valuation model is tested by examining how well the model captures the true values of early exercise premium. Mispricing of early exercise premium can be assessed by comparing modelpredicted values of early exercise premium to market values of early exercise premium. The computations are performed using both historical volatility (HV) and implied volatility (IV). Table 5 shows the mispricing of early exercise premium by moneyness for American put options on OEX Index for the period $01 / 03 / 1995-01 / 03 / 2005$. The values in parentheses are mean values of the mispricing expressed as a percent of the market value of early exercise premium. For all options, only about $33 \%$ of the market value of early exercise is captured by the MBAW model with IV. For out-of-the-money options, more than $82 \%$ of the market value of early exercise is not captured by this model, whereas nearly $53 \%$ of the early exercise premium is not accounted for when the option is in-the-money. This large mispricing of early exercise premium for put options regardless of moneyness seems to explain the significantly high pricing biases reported in Table 4.

TABLE 6: Regression Results: The market value of early exercise premium, $E E P_{m k t}$, is regressed over the theoretical value of early exercise premium, $E E P_{m d l}$, for put options on OEX Index: 01/03/1995 - 01/03/2005.

$$
E E P_{m k t}=\lambda_{1}+\lambda_{2}\left(E E P_{m d l}\right)+\omega
$$

\begin{tabular}{ccccc}
\hline Model & All Observations & $\lambda_{1}$ & $\lambda_{2}$ & $A d j-R^{2}$ \\
\hline MBAW & 118,941 & -1.68735 & 0.62476 & 0.70135 \\
(H.V.) & & $(-6.9381)$ & $(49.5137)$ & \\
CJM & 118,941 & -1.62067 & 0.62926 & 0.70120 \\
(H.V.) & & $(-3.8527)$ & $(27.3643)$ & \\
MBAW & 118,941 & -0.98684 & 0.54234 & 0.73694 \\
(I.V.) & & $(-6.7985)$ & $(36.5764)$ & \\
CJM & 118,941 & -0.91073 & 0.54298 & 0.73158 \\
(I.V.) & & $(-5.2941)$ & $(22.3641)$ & \\
\hline
\end{tabular}

The market values of early exercise premium are defined as observed market price of American put option minus the European put value of the option derived from put/call parity. The theoretical value of early exercise premium is computed as the difference between (1) the model price estimated using either the MBAW model or the CJM model, and (2) the Black-Scholes model price. Implied volatility and historical volatility are designated by (I.V.) and (H.V.) respectively. The values in parentheses are t-statistics computed by setting $\lambda_{1}=$ 1 and $\lambda_{2}=1$. 
To investigate further the quality of the MBAW and the CJM models with both measures of volatility, market values of early exercise premium is regressed over model-predicted values of early exercise premium. Under the null hypothesis that the model-predicted early exercise premium perfectly forecasts the true market value of early exercise premium, the intercept and slope coefficients are expected to equal zero and one respectively. The regression results appear in Table 6 . The values in parentheses are t-statistics computed by setting the intercept and slope coefficients to zero and one respectively. The statistically significant t-values reported for both coefficients suggest that the null hypothesis is rejected. The explanatory power of the regression as provided by the Adjusted- $R^{2}$ indicates that more than $70 \%$ and more than $73 \%$ of the variation in the market value of early exercise premium can be explained by the two models under HV and IV respectively. Overall, the results from the quality test suggest that both American put valuation models do not properly capture the value of early exercise embedded in American put prices. The ability of these models to capture the value of early exercise is particularly weak for out-of-themoney put options.

\section{Conclusions}

This paper examines empirically the value of early exercise for American put options. Market values of early exercise premium for put options on S\&P 100 Index are directly derived from observable market prices of put options using the European put-call parity relationship. For the period 01/03/1995 - 01/03/2005, the mean market value of early exercise was about $\$ 7.44$ per option or $9.55 \%$ of the option price. Consistent with prior empirical evidence, early exercise premium for out-of-the-money put options is not significant. Consistent with the theory, the value of early exercise found is significantly positively related to the time to maturity and to the volatility of the underlying Index, and significantly negatively related to moneyness and interest rates.

The quality of the American put option pricing models developed by (1) McMillan (1986) \& Barone-Adesi and Whaley (1987) and (2) Carr, Jarrow and Myneni (1992) are tested by investigating the proportion of early exercise premium captured by the model-predicted prices. The results indicate that for all options, on average, about $35 \%$ of the market value of early exercise is captured by either the MBAW model or the CJM model. Hence, the MBAW and the CJM American put valuation models do not fully capture the value of early exercise embedded in American put prices. These models ability to capture the value of early exercise is particularly weak for out-of-the-money put options.

Assuming that the MBAW and CJM models correctly price at-the-money put options, a performance test is conducted comparing model-predicted prices to observed market prices. The result is that both American valuation models significantly misprice options regardless of moneyness. These pricing biases are mainly due to the misvaluation of early exercise premium and the misspecification of the Black-Scholes model. The results of this study lead to conclude that the 
MBAW and the CJM American put valuation models predictions of put option market prices are acceptable.

Author statement: Aku Doffu is an associate professor of finance, John F. Welch College of Business, Sacred Heart University, United States. E-mail: adoff21@ yahoo.com. This paper was reviewed anonymously, and then edited to conform to the format of the Journal. The author wishes to record his appreciation to its editorial office for the invitation to submit this paper when it was presented at the 2007 FMA conference. The author takes full responsibility for the remaining errors.

\section{References}

Barone-Adesi, Giovanni, and Robert E. Whaley, 1987, "Efficient Analytic Approximation of American Option Values," Journal of Finance 42: 301320.

Black, Fischer, and Myron S. Scholes, 1973, "The Pricing of Options and Corporate Liabilities," Journal of Political Economy 81: 637-654.

Brenner, Menachem, and Dan Galai, 1986, “Implied Interest Rates," Journal of Business 59: 493-507.

Carr, Peter, Robert Jarrow, and Ravi Myneni, 1992, “Alternative Characterizations of American Put Options," Mathematical Finance 2: 87-105.

Dueker, Michael, and Thomas W. Miller Jr., 2003, "Directly Measuring Early Exercise Premiums Using American and European S\&P 500 Index Options," The Journal of Futures Market 23: 287-325.

Dueker, Michael, and Thomas W. Miller Jr., 1996, "Market Microstructure Effects on the Direct Measurements of the Early Exercise Premium in Exchange-Listed Options," Federal Reserve Bank of St. Louis.

Geske, Robert, and H. E. Johnson, 1984, "The American Put Valued Analytically," Journal of Finance 39: 1511-1524.

Harvey, Campbell R., and Robert E. Whaley, 1992, "Market Volatility Prediction and the Efficiency of the S\&P 100 Index Option Market," Journal of Financial Economics 31: 43-73.

Jorion, Philippe, and Neal M. Stoughton, 1989, “An Empirical Investigation of the Early Exercise Premium of Foreign Currency Options, Journal of Futures Market 9: 365-375.

Loudon, G. F., 1990, “American Put Pricing: Australian Evidence,” Journal of Business Finance \& Accounting 17: 297-321.

MacMillan, L. W., 1986, "An Analytic Approximation for the American Put Option," Advances in Futures and Options Research 1: 141-183.

Rhim, Jong C., and Yong H. Kim, 2000, "An Estimation of Early Exercise Premium for American Put Options," Global Business and Finance Review 5: 13-30. 
Shastri, Kuldeep, and Kishore Tandon, 1986, “An Empirical Test of a Valuation Model for American Options on Futures Contracts," Journal of Financial and Quantitative Analysis 21: 377-392.

Whaley, Robert E., 1986, "Valuation of American Futures Options: Theory and Empirical Tests," Journal of Finance 41: 127-150.

Zivney, Terry L., 1991, "The Value of Early Exercise in Option Prices: An Empirical Investigation," Journal of Financial and Quantitative Analysis 26: 129-138. 